\title{
BMJ Global Health Immunisation financing and programme performance in the Middle East and North Africa, 2010 to 2017
}

\author{
Helen Saxenian, ${ }^{1}$ Nahad Sadr-Azodi, ${ }^{2}$ Miloud Kaddar, ${ }^{3}$ Kamel Senouci ${ }^{4}$
}

To cite: Saxenian $\mathrm{H}$, Sadr-Azodi N, Kaddar M, et al. Immunisation financing and programme performance in the Middle East and North Africa, 2010 to 2017. BMJ Glob Health 2019;4:e001248. doi:10.1136/ bmjgh-2018-001248

Handling editor Seye Abimbola

Received 23 October 2018 Revised 29 December 2018 Accepted 4 January 2019

Check for updates

(c) Author(s) (or their employer(s)) 2019. Re-use permitted under CC BY-NC. No commercial re-use. See rights and permissions. Published by BMJ.

${ }^{1}$ Independent consultant, Bethesda, Maryland, USA ${ }^{2}$ United Nations Children's Fund Regional Office for the Middle East and North Africa, Amman, Jordan

${ }^{3}$ President, MK International Consulting, Villejuif, France ${ }^{4}$ United Nations Children's Fund, Regional Office for the Middle East and North Africa, Amman, Jordan

Correspondence to Dr Helen Saxenian; helensaxenian@gmail.com

\section{ABSTRACT}

Immunisation is a cornerstone to primary health care and is an exceptionally good value. The 14 low-income and middle-income countries in the Middle East and North Africa region make up $88 \%$ of the region's population and $92 \%$ of its births. Many of these countries have maintained high immunisation coverage even during periods of low or negative economic growth. However, coverage has sharply deteriorated in countries directly impacted by conflict and political unrest. Approximately 1.3 million children were not completely vaccinated in 2017 , as measured by third dose of diphtheria-pertussis-tetanus vaccine. Most of the countries have been slow to adopt the newer, more expensive life-saving vaccines mainly because of financial constraints and the socioeconomic context. Apart from the three countries that have had long-standing assistance from Gavi, the Vaccine Alliance, most countries have not benefited appreciably from donor and partner activities in supporting their health sector and in achieving their national and subnational immunisation targets. Looking forward, development partners will have an important role in helping reconstruct health systems in conflict-affected countries. They can also help with generating evidence and strategic advocacy for high-priority and cost-effective services, including immunisation. Governments and ministries of health would ensure important benefits to their populations by investing further in their immunisation programmes. Where possible, the health system can create and expand fiscal space from efficiency gains in harmonising vaccine procurement mechanisms and service integration; broader revenue generation from economic growth; and reallocation of government budgets to health, and from within health, to immunization.

\section{INTRODUCTION}

Many of the countries in the Middle East and North Africa (MENA) region have been directly and indirectly impacted by turmoil, with Iraq, Libya, the Syrian Arab Republic (henceforth, Syria) and Yemen in civil war and millions of refugees fleeing to neighbouring countries. Armed conflict, political unrest and terrorism have destabilised economic growth, trade and tourism. The 2014 oil price shock hit oil producers in the region, such as Algeria and the Islamic Republic of Iran (henceforth,

\section{Summary box}

The conflict-affected countries have had sharp declines in immunisation coverage, as measured by diphtheria-tetanus-pertussis third dose (DTP3) coverage.

- Many of the countries that have maintained high DTP3 coverage have been slow to adopt the newer, more expensive WHO-recommended vaccines because of financial constraints and the socioeconomic context.

- Governments and ministries of health would ensure important benefits to their populations from investing further in their immunisation programmes.

- External assistance for the countries in the region affected by conflicts, war and economic turmoil remains far from adequate in helping governments cover pressing basic social and health needs, such as immunisation. Looking forward, development partners should play an important role in helping reconstruct health systems, including immunisation, in conflict-affected countries.

Iran), hard. The MENA region has some of the world's highest rates of youth unemployment. ${ }^{1}$ International sanctions have been imposed on some of the countries including, for example, Iran, the Sudan (henceforth, Sudan) and Syria. In this unstable context, we examine how immunisation-a cornerstone of primary healthcare-has fared. Immunisation is an exceptionally good investment in health, returning many more dollars in benefits for every dollar spent. ${ }^{2}$ Have governments managed to protect these services, even in times of constricting budgets? Have governments managed to improve the coverage and scope of these critical programmes? This paper assesses the performance of the 14 low-income and middle-income countries in the MENA region in achieving high and equal coverage among socioeconomic and geographical groups and in introducing new lifesaving vaccines in recent years (2010 to 2017). It focuses on what we can learn about 
the financing challenges faced by countries and how they might be addressed looking forward.

The MENA region consists of 6 high-income, 12 middle-income and 2 low-income countries, according to the World Bank's most recent income classification. ${ }^{3}$ For the purposes of this paper, State of Palestine (henceforth, Palestine) is included as one of the 12 middle-income countries (MICs). Countries are classified as low income if their 2017 gross national income per capita (GNI p.c.) is US $\$ 995$ or less, as middle income if their GNI p.c. is between US $\$ 996$ and US $\$ 12055$, and high income if their income is above US $\$ 12056 .{ }^{3}$ This paper focuses on the 12 MICs, Algeria, Djibouti, Egypt, Iran, Iraq, Jordan, Lebanon, Libya, Morocco, Palestine, Sudan and Tunisia, and the two recently reclassified low-income countries, Yemen and Syria. Gavi, the Vaccine Alliance (henceforth, Gavi) is almost the sole source of external assistance for immunisation in the region. Most countries do not receive any external assistance for immunisation. Only three (Djibouti, Sudan and Yemen) have been eligible for support from Gavi though Syria has become fully eligible for Gavi assistance in 2019 given its recent income reclassification.

\section{How has immunization performance fared recently?}

Immunisation performance has multiple dimensions, including overall coverage, coverage distribution and the availability of vaccines in the national schedule. Overall coverage is typically measured by the percentage of children receiving their third dose of diphtheria-pertussistetanus containing vaccine (DPT3) according to WHO and UNICEF estimates. Coverage distribution refers to the reach to vulnerable subgroups categorised, for example, by income, race, ethnicity, disability, religion, migratory status and location. This is typically measured by household surveys or administrative data. The vaccines in the national schedule-compared with WHO's recommended vaccines-is another performance dimension. Traditional vaccines, such as oral polio, have been manufactured for decades and can be purchased at low prices. The newer vaccines that are WHO- recommended, such as rotavirus, pneumococcal conjugate and human papillomavirus (HPV) vaccines, are more expensive and can be a challenge for countries to introduce.

\section{Coverage trends}

In 2017 , the 14 countries accounted for about 10.7 million births of 141 million births globally and 1.29 million unvaccinated/undervaccinated children of 19.9 million globally. ${ }^{45}$ Nearly $95 \%$ of the unvaccinated/undervaccinated children were concentrated in six countries: Iraq, Yemen, Syria, Egypt, Algeria and Sudan.

Many countries have strong and relatively consistent immunisation performance as measured by DTP3 coverage. These include Algeria, Egypt, Iran, Jordan, Libya, Morocco, Sudan, Palestine and Tunisia, all with at least 90\% DTP3 coverage, across the period 2010 to 2017 (figure 1A). ${ }^{5}$ On the other hand, Iraq, Syria and Yemen, which have been impacted by prolonged conflicts and civil wars, have seen significant drops, with Syria showing the largest from $80 \%$ to $48 \%$ (figure 1B). Djibouti has struggled to bring its coverage above $90 \%$ and has seen a drop from $88 \%$ to $68 \%$.

\section{Coverage distribution}

DTP3 coverage across districts is used to demonstrate geographical disparities. It is country-reported to WHO and UNICEF annually on the 'Joint Reporting Form (JRF).${ }^{6}$ In 2017, Djibouti, Egypt, Iraq, Sudan, Syria and Yemen were well below the Global Vaccine Action Plan (GVAP) target $^{7}$ of percentage of districts at or greater than $80 \%$ DTP3 coverage.

Household surveys can highlight coverage challenges. In Yemen, the 2013 Demographic and Health Survey results found that DTP3 coverage was 54\% in rural areas compared with $77 \%$ in urban. ${ }^{8}$ While in most countries urban areas have higher immunisation coverage than rural areas, residence in urban slums, particularly for recent migrants, puts children at greater risk of vaccine-preventable diseases due to low coverage. ${ }^{9}$ Urban slums are typically inhabited by households with low income and education levels and they may have insecure legal status. They are often poorly served by public services, and may be at increased risk of waterborne and vectorborne diseases.

Household surveys highlight that immunisation coverage can be unequal by wealth quintiles. In Sudan, the 2014 Multiple Indicator Cluster Survey results showed that DTP3 coverage was $23 \%$ for the poorest quintile, compared with $86 \%$ for the wealthiest quintile. ${ }^{8}$

\section{New vaccine introductions}

There are considerable differences in the uptake of WHO-recommended vaccines in the region. Many countries that have maintained high levels of DTP3 coverage have not managed to introduce many of the newer vaccines.

Gavi has been providing funding for new vaccine introductions, operational costs of campaigns, cold chain and health system strengthening in Djibouti, Sudan and Yemen. With that support, these countries have introduced pentavalent, pneumococcal conjugate and rotavirus vaccines. Yemen and Sudan have also introduced measles-rubella (MR) and meningitis A vaccines, respectively, ${ }^{10}$ and there are plans for Sudan to introduce yellow fever, MR and possibly HPV vaccines in coming years. All three countries procure their vaccines through UNICEF Supply Division at favourable prices. While not formally Gavi-eligible over the period under review, the Gavi Board approved selected vaccines and cold chain support to Syria for up to US\$25 million in 2017 and 2018, channelled primarily through UNICEF. ${ }^{11}$ However, given its recent income reclassification and Gavi's eligibility guidelines, Syria has become eligible in 2019 for full Gavi assistance. 

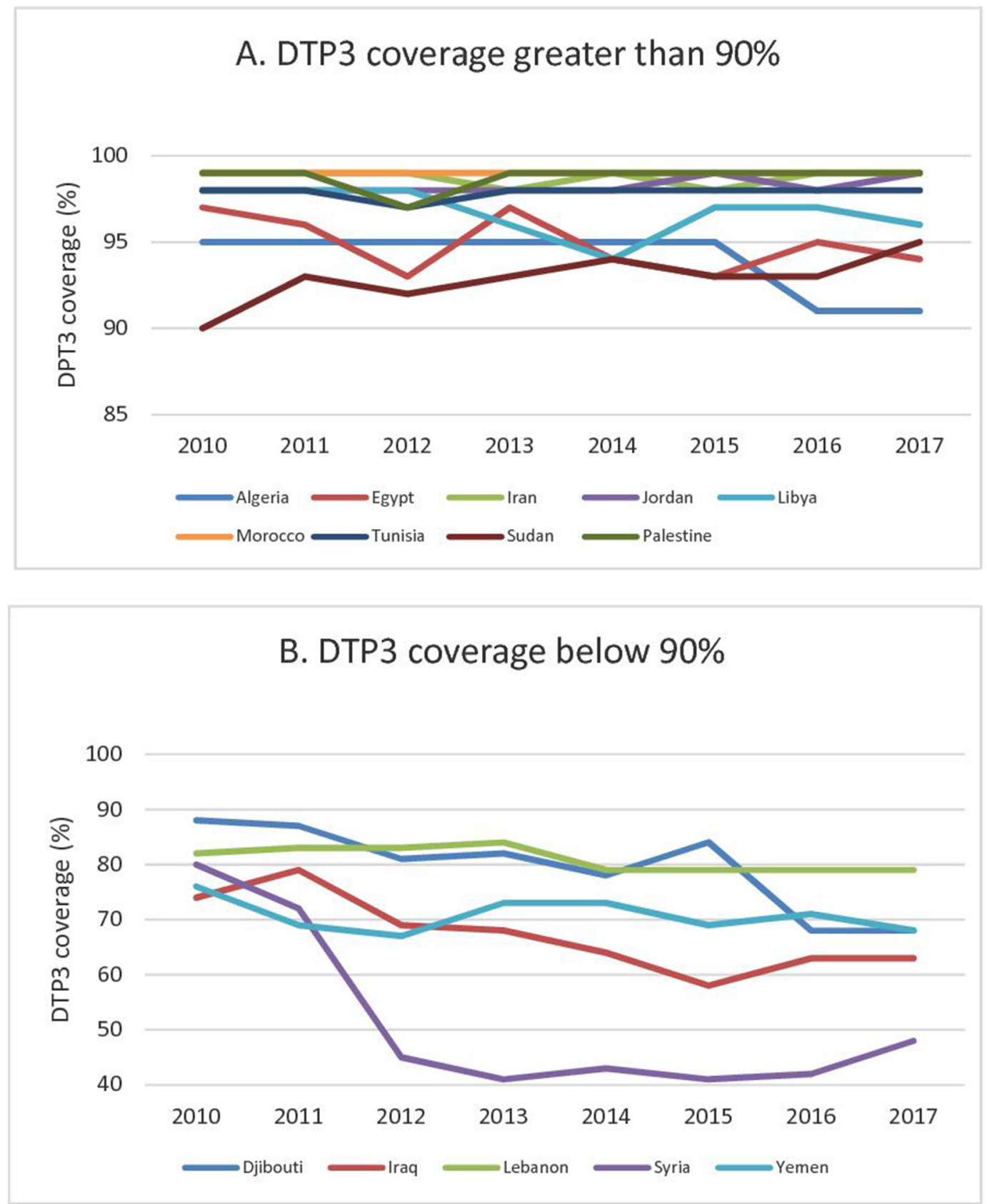

Figure 1 DTP3 coverage, 2010-2017. Source: WHO (http://apps.who.int/immunization_monitoring/globalsummary/ wucoveragecountrylist.html). For Palestine, data from UNICEF (https://data.unicef.org/topic/child-health/immunization/).

Figure 2 shows the introduction year of pneumococcal conjugate and rotavirus vaccines. ${ }^{12}$ Among the non-Gavi-eligible countries, Morocco is the earliest adopter of these vaccines, with both introductions in 2010. Libya has introduced both as well, but the remaining non-Gavi-eligible countries, including Egypt with the largest birth cohort in the region, have lagged behind on one or both vaccines. In most cases, the national immunisation technical advisory groups have prioritised these vaccines for introductions, but budgetary room has not been created to finance them. HPV vaccine has only been introduced in Libya to date.
Conflict

Immunisation performance needs to be reviewed in the context of the direct and indirect impacts of conflict on populations, particularly the disadvantaged and vulnerable. Children affected by conflict suffer disproportionately from disease outbreaks. Of the 3400 polio cases reported globally from 2010 to $2016,70 \%$ were in conflict-affected countries. ${ }^{13}$ According to the United Nations Refugee Agency (UNHCR) population statistics, as of end 2017, there were 20.8 million persons of concern in the MENA region, representing around 29\% of the 71.4 million globally. Persons of concern include refugees, asylum-seekers, returned refugees, internally displaced persons (IDPs), returned IDPs, stateless people 


\begin{tabular}{|c|c|c|c|c|c|c|c|c|c|}
\hline \multirow{2}{*}{\multicolumn{2}{|c|}{ Gavi-eligible countries }} & 2010 & 2011 & 2012 & 2013 & 2014 & 2015 & 2016 & 2017 \\
\hline & & & & & & & & & \\
\hline \multirow[t]{2}{*}{ Djibouti } & PCV & & & & & & & & \\
\hline & Rotavirus & & & & & & & & \\
\hline \multirow[t]{2}{*}{ Sudan } & PCV & & & & & & & & \\
\hline & Rotavirus & & & & & & & & \\
\hline \multirow[t]{2}{*}{ Yemen } & PCV & & & & & & & & \\
\hline & Rotavirus & & & & & & & & \\
\hline \multicolumn{10}{|c|}{\begin{tabular}{|l|} 
Non Gavi-eligible countries \\
\end{tabular}} \\
\hline \multirow[t]{2}{*}{ Algeria } & PCV & & & & & & & & \\
\hline & Rotavirus & & & & & & & & \\
\hline \multirow[t]{2}{*}{ Egypt } & PCV & & & & & & & & \\
\hline & Rotavirus & & & & & & & & \\
\hline \multirow[t]{2}{*}{ Iran } & PCV & & & & & & & & \\
\hline & Rotavirus & & & & & & & & \\
\hline \multirow[t]{2}{*}{ Iraq } & PCV & & & & & & & & \\
\hline & Rotavirus & & & & & & & & \\
\hline \multirow[t]{2}{*}{ Jordan } & PCV & & & & & & & & \\
\hline & Rotavirus & & & & & & & & \\
\hline \multirow[t]{2}{*}{ Lebanon } & PCV & & & & & & & & \\
\hline & Rotavirus & & & & & & & & \\
\hline \multirow[t]{2}{*}{ Libya } & PCV & & & & & & & & \\
\hline & Rotavirus & & & & & & & & \\
\hline \multirow[t]{2}{*}{ Morocco } & PCV & & & & & & & & \\
\hline & Rotavirus & & & & & & & & \\
\hline \multirow[t]{2}{*}{ Syria* } & PCV & & & & & & & & \\
\hline & Rotavirus & & & & & & & & \\
\hline \multirow[t]{2}{*}{ Tunisia } & PCV & & & & & & & & \\
\hline & Rotavirus & & & & & & & & \\
\hline
\end{tabular}

Figure 2 Year of introduction (in green) of pneumococcal conjugate (PCV) and rotavirus vaccines by Gavi eligibility. The Gavi Board approved some support for Syria on an exceptional basis, but it was not Gavi-eligible during the period. Source: WHO (http://www.who.int/immunization/monitoring_surveillance/data/en/). Data unavailable for Palestine.

and others of concern. Of those in MENA, 34\% were found in Syria, $22 \%$ in Iraq, $16 \%$ in Sudan and $12 \%$ in Yemen. ${ }^{14}$

One out of six people in Lebanon was a refugee who was under the mandate of UNHCR. With that ratio, Lebanon continues to host the largest number of refugees as share of its population of any country in the world. When Palestinian refugees under the umbrella of the United Nations Relief and Works Agency are included, the number rises to one in four. One in 14 people in Jordan was a refugee under the mandate of UNHCR; this rises to one in three if Palestinian refugees are included..$^{15}$ In a recent analysis, it is estimated that Jordan's spending on refugees is nearly $2.25 \%$ of its gross domestic product (GDP) annually, or approximately $9 \%$ of its non-interest government expenditure. ${ }^{16}$ The estimates are probably conservative as they do not take into account hundreds of thousands of unregistered refugees and their budget impact.

\section{How are economic growth, government health expenditures and immunisation financing linked?}

Economic growth and health expenditure

Since immunisation generates positive externalities and is widely accepted as a public responsibility, it is typically financed primarily from government expenditure. Sources of government expenditure include government revenue (mainly from taxes), borrowing and grants. Tax and hence government revenues increase with economic growth. As countries develop, the tax base generally expands and tax administration improves. On the other hand, economic downturns constrict government revenue leading to borrowing and/or decreased expenditure. Governments make decisions, among various competing obligations, about how much budget to allocate to the health sector and within the sector, to different areas, for example, between primary and tertiary care. In the MENA region, some countries have lost ground, in real terms, in government spending on health from domestic sources p.c. over 


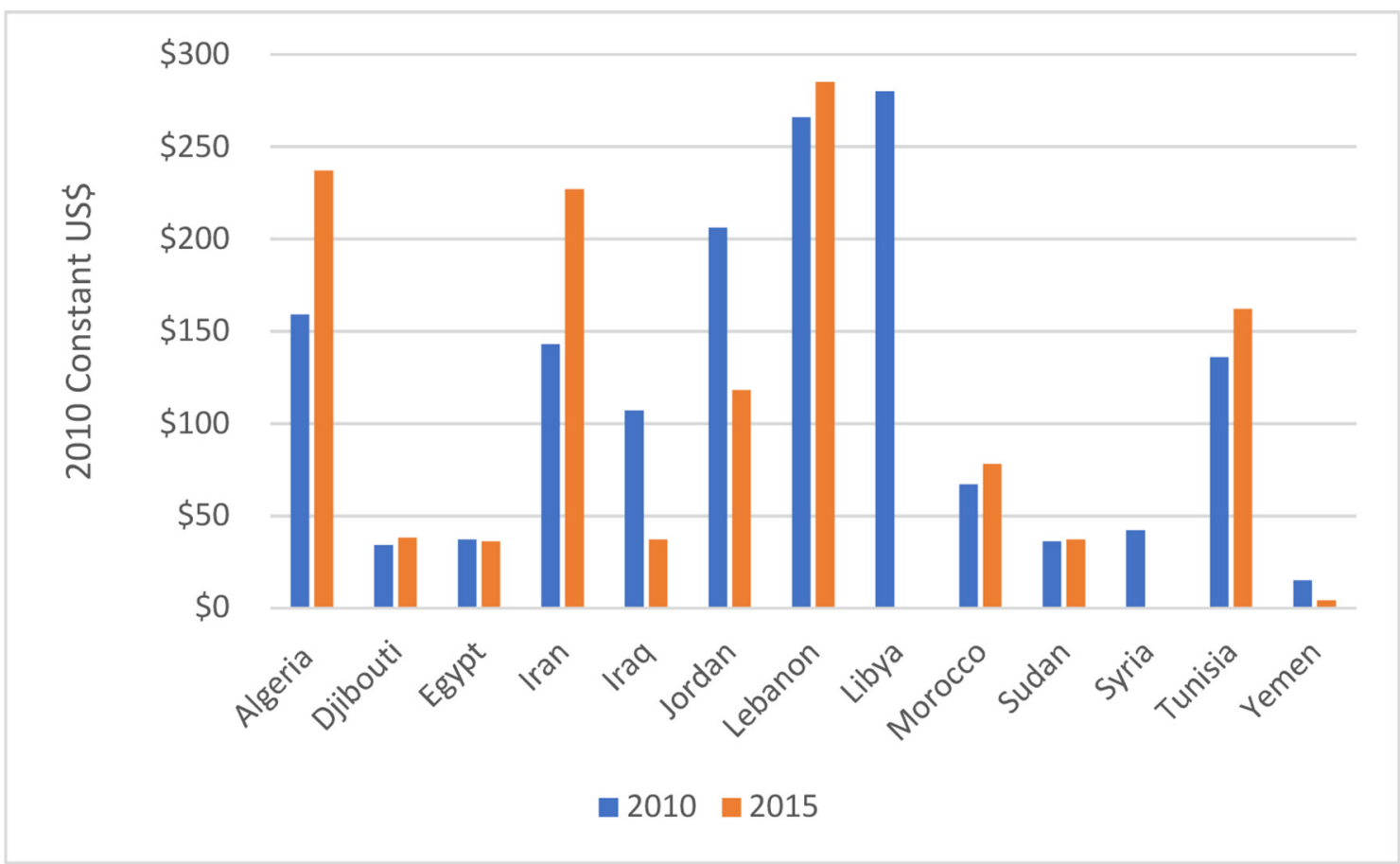

Figure 3 Government expenditure on health from domestic sources per capita, 2010 and 2015. Source: health expenditure data from WHO Global Health Expenditure Database, accessed 1 Jun 2018 (http://apps.who.int/nha/database/Home/Index/ en). Data available through 2015. Data unavailable for Palestine. Data unavailable for Libya and Syria in 2015.

the period (figure 3). Stuckler et al found that political commitment, higher tax revenue and greater democracy scores are all associated with a larger share of GDP translating to government spending on health. ${ }^{17}$ This is relevant for the MENA region given the relatively low ranking of many of the countries on democracy indices. ${ }^{18}$

Economic growth was volatile and/or low or strongly negative in some years in some countries, including Iran, Iraq, Lebanon, Libya, Sudan, Tunisia and Yemen over the period. ${ }^{19}$ There is large variation in government expenditure on health from domestic sources p.c. (figure 3). ${ }^{20}$ Lebanon is the highest at US\$285 in 2015, compared with only US\$4 in Yemen. Lebanon's highest spending is commensurate with its GNI p.c., which is the highest among MICs in the region, at US $\$ 7930$ in 2015 according to World Bank data. ${ }^{21}$ Yemen's already very low level of government expenditure on health p.c. from domestic sources has fallen by more than two-thirds since 2010 , from US $\$ 15$ to US $\$ 4$ in 2015 (all figures in constant 2010 US\$). Other countries with sharp declines include Syria, Libya, Iraq and Jordan. Djibouti, Egypt, Lebanon and Sudan have generally faced a flat trend. There have been exceptions. For example, expenditures have increased by $50 \%$ or more in Algeria and Iran, and by $20 \%$ in Tunisia in real terms. These indicators underscore both the diversity in public sector resource availability for health and the highly constrained budget situation in many governments in MENA.

\section{Immunisation financing}

Countries estimate and report expenditures on vaccines for routine immunisation and total spending for immunisation through the WHO-UNICEF JRF. ${ }^{22}$ The JRF data on the percentage of routine vaccine expenditures covered by government (figure 4) reinforce the picture that many countries (Algeria, Egypt, Iran, Jordan, Lebanon, Morocco and Tunisia) are managing to steadily cover the annual cost of vaccines, while the external aiddependent countries, Djibouti, Syria, Sudan and Yemen, cover a portion of it. Syria reported financing only $9 \%$ of vaccine costs in 2017 with the bulk of vaccines costs defrayed through an exceptional Gavi assistance mechanism. By value, Gavi has disbursed about US $\$ 7.2$ million to Djibouti, US $\$ 383.8$ million to Sudan and US\$242.7 million to Yemen from 2000 to August 2018. ${ }^{10}$ These countries 'co-finance' routine vaccines that are supported by Gavi. 'Co-financing' means that countries procure a defined number of doses each year through UNICEF Supply Division and Gavi procures the balance. Yemen has had its co-financing requirement waived recently given the civil war. ${ }^{23}$

Given Sudan's income growth, it is expected to enter the accelerated transition phase from Gavi in 2020 and reach full domestic financing by 2025. Sudan will need to address the significant disparities in immunisation coverage and make budgetary room for financing traditional vaccines as external support for these vaccines may end as well. If not properly planned and handled, Sudan could face a disruption in vaccine procurement with consequences on vaccine stockouts, service delivery and coverage.

Another way to examine government expenditures on vaccines is to look at these expenditures as a percentage 
of all government expenditures on health from domestic sources and per surviving infant. Figure 5 presents both these data for 2015. Of the countries in the figure, the highest spending on vaccines as a percentage of government expenditure on health is Morocco $(1.7 \%)$ and the lowest is Djibouti $(0.1 \%)$. Morocco has strongly prioritised immunisation within the health budget as evidenced by its early introduction of new vaccines. Morocco is fully financing its vaccines; Djibouti is still heavily reliant on external assistance. Vaccine expenditures per surviving infant range from only $\$ 1$ in Yemen to about $\$ 94$ in Jordan. Jordan has the highest vaccine expenditure per surviving infant, yet it has still not managed to introduce PCV (figure 2).

Differences in country income levels, government expenditures on health from domestic sources, government expenditures on vaccines per surviving infant, procurement approaches and the availability of external assistance only go so far in explaining variations in coverage levels and adoption of new vaccines in MENA countries. The presence of conflict is another important factor. And so is leadership. Although its income and government expenditure on health are far lower than several other MENA MICs, Morocco was the earliest adopter of rotavirus and pneumococcal conjugate vaccines, on the basis of strong leadership and advocacy, and the fact that it would help Morocco achieve the Millenium Development Goals 4 and $5 .^{24}$

\section{How are vaccines procured in the region and what impact does this have on costs and new introductions?}

Vaccines are a large share of immunisation programme costs and how they are procured can impact budget requirements. The three long-standing Gavi-eligible countries use UNICEF Supply Division procurement services. The non-Gavi-eligible countries carry out some or all of their procurement on the world market. Countries including Egypt, Iraq, Lebanon, Morocco and Palestine use the procurement services of UNICEF Supply Division for a number of their routine vaccines. Iran and Egypt locally produce a few traditional vaccines. ${ }^{25}$ Countries report data on vaccine prices to WHO and UNICEF on the $\mathrm{JRF}$, and there is large variation in prices obtained for the same vaccines. Furthermore, there is some evidence that non-Gavi MICs in MENA are paying higher prices than non-Gavi MICs in other regions for several vaccines. ${ }^{26}$ Some of the important factors underlying price variation are country income level, choice of vaccine formulation and presentation, volumes purchased, contract duration, payment terms, country-required administrative procedures and supplier strategies. Countries may be able to review and modify their regulatory and procurement approaches to make quality vaccines more affordable, generating budgetary room for other needs including new vaccine introductions.

\section{CONCLUSIONS}

Many of the low-income and middle-income countries in the MENA region have experienced a combination of low and volatile economic growth, ongoing conflict and political unrest-all factors that place pressure on government budgets and programmes, including health and immunisation. ${ }^{27}$ Conflicts have also impacted the neighbouring countries especially from the need to absorb and provide services to large numbers of displaced populations. Syria

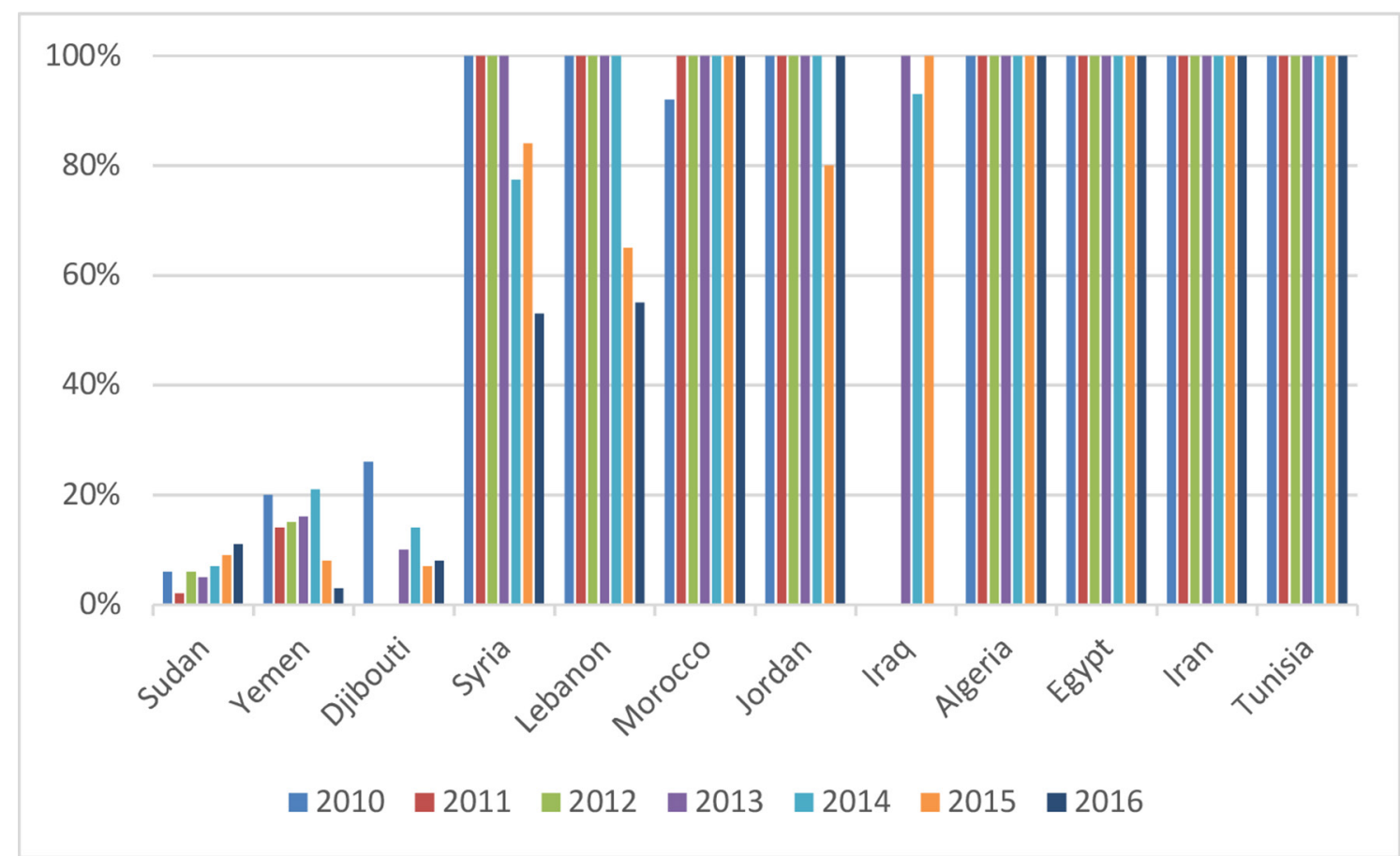

Figure 4 Percentage of routine vaccine expenditures reported as covered by government, 2010-2016. Source: WHO-UNICEF Joint Reporting Form. No data reported for Libya and Palestine, so they are omitted from the table. Some of the data are estimates from WHO (http://www.who.int/immunization/programmes_systems/financing/data_indicators/en/). 
and Iraq, both in prolonged conflicts, have faced sharp declines in their DTP3 coverage since 2010. Yemen and Djibouti have also seen significant falls in coverage. But the majority of countries have impressively maintained high coverage over the period, meeting the GVAP target of DTP3 coverage of at least $90 \%$.

Countries doing well on coverage, however, have had challenges in introducing new vaccines that have been recommended by WHO, such as rotavirus and pneumococcal conjugate vaccines. They are in particular lagging behind the three long-standing Gavi-supported countries on introductions. Libya and Morocco are exceptions as both countries have introduced these vaccines. Libya has introduced HPV as well. This was aided by high-level political support and commitment. Morocco's reported expenditure on vaccines show that it is allocating the largest share of the government health budget from domestic sources to vaccines, at $1.7 \%$ (figure 5).

In the remaining countries, governments could create budgetary room for new vaccine introductions or for financing activities to improve coverage and reduce disparities either by reprioritising budgets away from lower priority activities to immunisation or by seeking cost savings in immunisation, for example, from modifying procurement mechanisms or synergising immunisation activities with other national health programmes. In terms of procurement, cost savings could be achieved in some countries through appropriate product presentation selection, more accurate vaccine forecasts, reductions in number of transactions per year, use of multiyear contracts and consideration to use existing procurement services (for some or all vaccines). At the same time, UNICEF Supply Division and partners can work with countries to explore the use of the Vaccine Independence Initiative or adapt commercial financing instruments to meet its prepayment requirement. ${ }^{28} \mathrm{It}$ is estimated that the cost of targeted technical assistance to non-Gavi-eligible MICs 'would come at a fraction of the cost of the investment made to subsidise vaccines in the poorest Gavi-eligible countries'. ${ }^{29}$ In this regard, Gavi is considering targeted assistance to these MICs as part of its strategy for 2021-2025.

External support from donors and international agencies for immunisation has not been significant in the region except for Egypt and Morocco (mostly in the past) and Syria, Djibouti, Sudan and Yemen at the

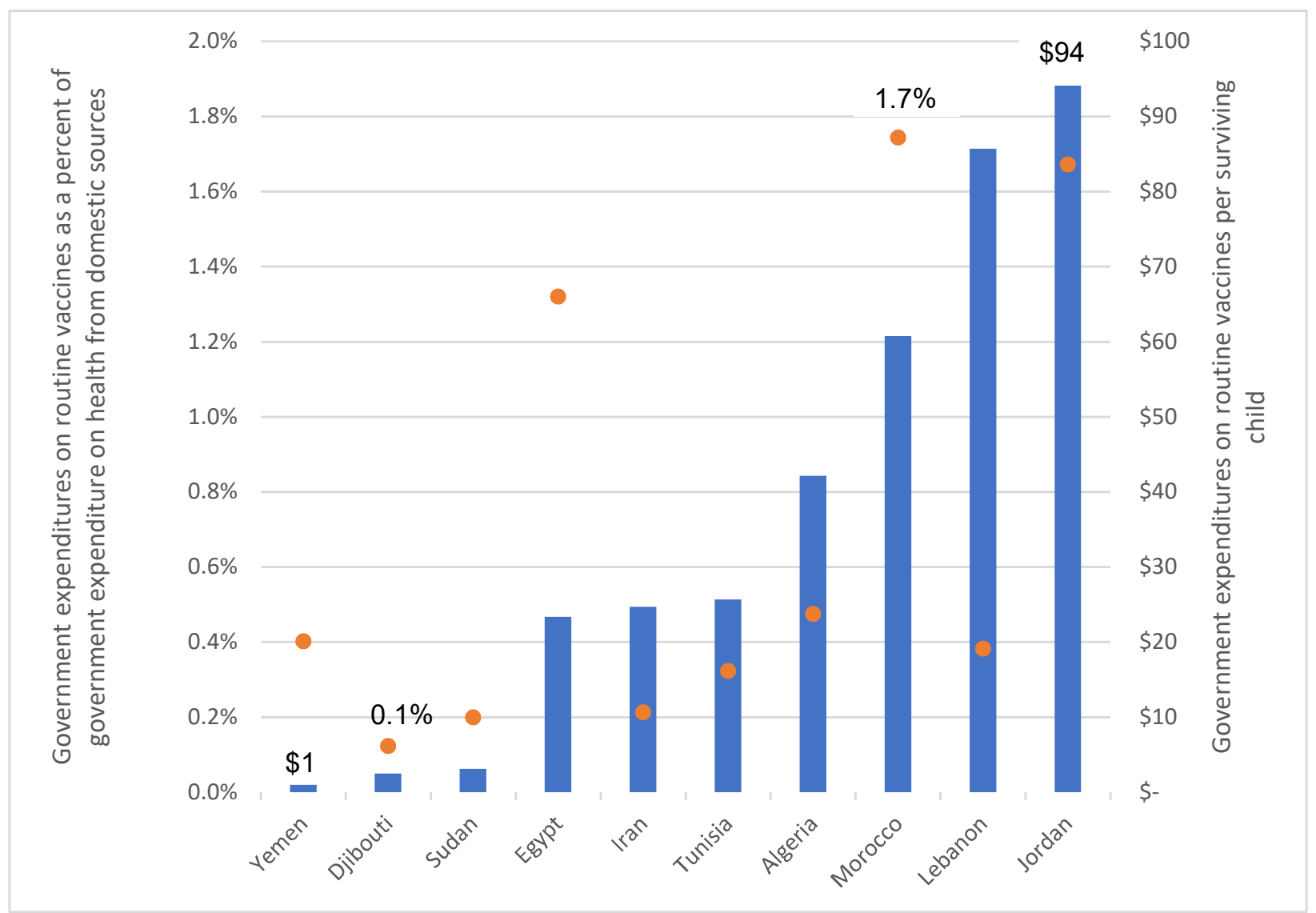

Figure 5 Reported government expenditures on routine vaccines per surviving infant and as a percentage of government expenditures on health from domestic sources, 2015 (2015 US\$). Sources: WHO-UNICEF Joint Reporting Form (JRF) for government expenditures on routine vaccines, 2015 (https://www.who.int/immunization/programmes_systems/financing/ data_indicators/en/WHO); Global Health Expenditure Database (GHED) for government expenditures on health from domestic sources, 2015 (http://apps.who.int/nha/database/Select/Indicators/en); UN World Population Prospects for number of surviving infants, 2015. Libya, Palestine and Syria excluded because of lack of data from WHO GHED for 2015. Iraq excluded because data on routine vaccine expenditure in the JRF appear to have major errors. 
present, almost entirely from Gavi. External assistance for countries affected by conflicts and war remains far from adequate in helping governments cover pressing basic social and health needs. ${ }^{27}$ Funding for refugees and emergency humanitarian response has been a significant challenge in recent years in Jordan, Lebanon and Yemen. In conflict areas, in the coming years, mediumto long-term rebuilding of health systems (and immunisation programmes) will require significant resources and technical and external assistance.

Acknowledgements The authors are grateful to the individuals who reviewed this article and provided helpful input, particularly Daniel Ngemera of UNICEF MENA Regional Office. Senior government health officials and other experts and individuals from international organisations took time out of their busy schedules to be interviewed.

Contributors This analysis stems in part from work that HS and MK did for NS-A and KS at UNICEF MENARO. This analysis paper takes the work further, with updates to the data and additional analysis. HS prepared the first draft of the paper and NS-A, MK and KS materially participated in revisions and redrafting. All participated in early brainstorming about the analysis.

Funding This work was supported in part by Gavi, the Vaccine Alliance.

Disclaimer The many individuals who contributed to the report may not endorse these views, and they bear no responsibility for any errors.

Competing interests None declared.

Patient consent for publication Not required.

Provenance and peer review Not commissioned; externally peer reviewed.

Open access This is an open access article distributed in accordance with the Creative Commons Attribution Non Commercial (CC BY-NC 4.0) license, which permits others to distribute, remix, adapt, build upon this work non-commercially, and license their derivative works on different terms, provided the original work is properly cited, appropriate credit is given, any changes made indicated, and the use is non-commercial. See: http://creativecommons.org/licenses/by-nc/4.0/.

\section{REFERENCES}

1. World Bank Middle East and North Africa region. MENA economic monitor. A new economy for the Middle East and North Africa, 2018.

2. Ozawa S, Clark S, Portnoy A, et al. Return on investment from childhood immunization in low- and middle-income countries, 2011-20. Health Aff 2016;35:199-207.

3. World Bank Country and Lending Groups. Available: https:// datahelpdesk.worldbank.org/knowledgebase/articles/906519-worldbank-country-and-lending-groups

4. United Nations Population Division, 2018. World population prospects 2017, medium variant. Available: https://esa.un.org/unpd/ wpp/ [Accessed 4 Aug 2018].

5. Underimmunized children as measured by not receiving the third dose of Diphtheria-Tetanus-Pertussis (DTP3) vaccine (WHO/UNICEF estimates), 2018. Available: http://apps.who.int/immunization monitoring/globalsummary/timeseries/tswucoveragedtp3.html [Accessed Sep 10 2018].

6. See information reported by member state in, 2018. Available: http://www.who.int/immunization/monitoring surveillance/data/en/ [Accessed 20 Sep 2018].
7. Global Vaccine Action Plan, 2011. Available: http://www.who.int/ immunization/global_vaccine_action_plan/GVAP_doc_2011_2020/ en/

8. WHO Health Equity Monitor Country Profiles database, 2018. Available: http://apps.who.int/gho/data/view.wrapper.HE-VIZ11a? lang=en\&menu=hide [Accessed 13 May 2018].

9. Crocker-Buque T, Mindra G, Duncan R. Immunization, urbanization, and slums: a review of evidence, UNICEF, 2016.

10. Gavi, the Vaccine Alliance, country hub, 2018. Available: http://www. gavi.org/country/ [Accessed 20 Sep 2018].

11. Gavi to support immunisation of children in Syria, 2016. Available: http://www.gavi.org/library/news/press-releases/2016/gavi-tosupport-immunisation-of-children-in-syria/

12. WHO Year of introduction of selected vaccines database, 2018. Available: http://www.who.int/immunization/monitoring_surveillance/ data/en/ [Accessed 20 Sep 2018].

13. Ricardo MM, Mindra G. Immunization inequities in conflict affected countries, discussion paper. New York: UNICEF, 2017.

14. UNHCR, 2018. Available: http://popstats.unhcr.org/en/persons_of_ concern [Accessed 20 Sep 2018]

15. UNHCR, 2017. Global trends: forced displacement in 2017. Available: http://www.unhcr.org/globaltrends2017/

16. Plant $\mathrm{M}, 2018$. Refugee spending and the macroeconomic program in Jordan. CGD note. Available: https://www.cgdev.org/publication/ refugee-spending-and-macroeconomic-program-jordan

17. Stuckler D, Feigl AB, Basu S. The political economy of universal health coverage. Background paper for the global symposium on health systems research. World Health Organization, 2010.

18. See The Economist Intelligence Unit's Demogracy Index at, 2018. Available: https://infographics.economist.com/2018/ Democracylndex/

19. See the indicator percent change GDP constant prices in the International Monetary Fund, World Economic Outlook, 2018. Available: https://www.imf.org/external/pubs/ft/weo/2018/01/ weodata/index.aspx [Accessed 13 May 2018]

20. WHO Global Health Expenditure Database, 2018. Available: http:// apps.who.int/nha/database [Accessed 6 June 2018]

21. World Bank, 2017. World development indicators. Available: http://databank.worldbank.org/data/reports.aspx?source=worlddevelopment-indicators [Accessed 1 Dec 2017].

22. WHO UNICEF Joint Reporting Form, 2018. Available: http://www. who.int/immunization/programmes_systems/financing/data indicators/en/ [Accessed 1 Feb 2018].

23. See Co-financing information fact sheet Yemen. Available: https:// www.gavi.org/country/yemen/documents/ [Accessed 23 Jan 2019].

24. Makinen M, Kaddar M, Molldrem V, et al. New vaccine adoption in lower-middle-income countries. Health Policy Plan 2012;27:ii39-49.

25. UNICEF, May 2018. Immunization Financing in MENA MiddleIncome Countries. Available: https://www.unicef.org/mena/reports/ immunization-financing-mena-middle-income-countries [Accessed 23 January 2019].

26. WHO, 2019. VP3: region fact sheet, working document November 2017. Available: https://www.who.int/immunization/programmes_ systems/procurement/v3p/platform/module2/V3P_Region_Fact_ Sheet_EMR.pdf?ua=1 [Accessed 22 Jan 2019].

27. IMF The Economic Impact of Conflicts and the Refugee Crisis in the Middle East and North Africa, 2016. Staff discussion note. Available: https://www.imf.org/external/pubs/ft/sdn/2016/sdn1608. pdf [Accessed Sep 2016].

28. See the expansion of the vaccine independence Initiative (VII): protecting children with life-saving supplies. Available: https://www. unicef.org/supply/files/INNOVATION_LAB_LFLT_Ver1_Single_Pages. pdf [Accessed 5 Feb 2019].

29. Kaddar M, Schmitt S, Makinen M, et al. Global support for new vaccine implementation in middle-income countries. Vaccine 2013;31-B81-96. 